\title{
Effect of weight loss on central systolic blood pressure in elderly community-dwelling persons
}

\author{
Ryuichi Kawamoto ${ }^{1,2}$, Katsuhiko Kohara ${ }^{3}$, Tateaki Katoh ${ }^{2,3}$, Tomo Kusunoki ${ }^{1,2}$, Nobuyuki Ohtsuka ${ }^{2}$, \\ Masanori Abe ${ }^{1}$, Teru Kumagi ${ }^{1}$ and Tetsuro Miki ${ }^{3}$
}

Central blood pressure (BP) has been shown to strongly associate with cardiovascular disease and outcome. Recent studies have demonstrated a relationship between changes in body size by exercise training and peripheral BP; however, the effect on changes in central BP is unknown. The aim of this study was to assess whether changes in body size are independently related to changes in central BP in the elderly. The subjects were 11 men (mean age, $68 \pm 6$ years) and 84 women (68 \pm 7 years) from a rural village. Before and at the end of the 12-week training program, metabolic variables, and first peak radial systolic BP (SBP1) and second peak radial SBP (SBP2) as estimates of central SBP, were obtained. Radial augmentation index (AI) was calculated as follows: ((SBP2 - diastolic BP (DBP))/(SBP1-DBP)) $\times 100(\%)$ and we used Al corrected at heart rate 75 per min (AI@75). After the 12-week training program, weight loss correlated strongly with reduction in brachial mean arterial pressure (MAP), radial SBP1, SBP2 and AI@75. After adjusting for confounding factors, weight loss was significantly and independently associated with each reduction in brachial MAP $(\beta=0.34, P=0.001)$, radial SBP1 $(\beta=0.31, P=0.002)$, SBP2 $(\beta=0.37, P<0.001)$ and $A 1 @ 75(\beta=0.36, P=0.001)$. These findings suggest that weight loss by a 12-week training program may be an effective strategy to improve central BP parameters among Japanese elderly persons.

Hypertension Research (2014) 37, 933-938; doi:10.1038/hr.2014.108; published online 26 June 2014

Keywords: augmentation index; body weight loss; elderly persons; second peak radial systolic blood pressure; walking exercise

\section{INTRODUCTION}

Central blood pressure (BP) is different from peripheral BPs. Several studies have demonstrated the superiority of central over traditional peripheral BP in the prediction of cardiovascular disease and outcome. ${ }^{1,2}$ Based on the results of studies that assessed central BP, we can also distinguish the specific class-effect of antihypertensive drugs on central BP beyond peripheral BP, as well as the potential underlying hemodynamic mechanisms. ${ }^{3,4}$ Recently, an automated device for estimating central $\mathrm{BP}$ has been introduced, namely, Omron HEM-9000AI (Omron Healthcare, Kyoto, Japan), ,,6 and the use of this device has been proposed in Japan; the technical simplicity and short sampling time of the method make it more feasible to screen large populations compared with previous methods. ${ }^{5-7}$

Exercise training is recommended for lowering body weight and peripheral BP because the relationship between body weight and hypertension $^{8,9}$ and the inverse relationship between physical activity and hypertension ${ }^{10,11}$ are well-known. Increased body weight, particularly abdominal fat, is an important factor of aging $^{12}$ that causes various cardiovascular abnormalities, ${ }^{13}$ including hypertension. ${ }^{14}$ Exercise training improves body size in the elderly. ${ }^{15,16}$ Recently, many studies have demonstrated a relationship between changes in body size by exercise training and brachial BP; ${ }^{17}$ however, the effects of changes in body size by exercise training on central BP are unknown. The current cross-sectional studies have demonstrated that central BP is inversely correlated with obesityrelated factors (for example, increased body weight and abdominal fat $)^{18-20}$ and the effects of weight loss strategies on central BP are controversial. ${ }^{21}$ In addition, few interventional studies in the elderly have addressed whether changes in central BP are mediated by changes in body size or metabolic profiles by exercise training.

The aim of the study was to evaluate whether the changes in body size are independently related to changes in central BP and pulsatile flow load as hemodynamic manifestations of arterial stiffness in the elderly.

\section{METHODS}

Subjects

The present study was designed as a part of the Nomura study (UMIN000010611). The study population was selected through a community-based annual check-up process from the Nomura health and welfare center in a rural town located in Ehime prefecture, Japan. Participants were enrolled in the study by public health nurses at the health and welfare center. Physical activity level of subjects, information on medical history, present conditions and information on drugs used were obtained by interview.

${ }^{1}$ Department of Community Medicine, Ehime University Graduate School of Medicine, Ehime, Japan; ${ }^{2}$ Department of Internal Medicine, Seiyo Municipal Nomura Hospital, Ehime, Japan and ${ }^{3}$ Department of Geriatric Medicine, Ehime University Graduate School of Medicine, Ehime, Japan

Correspondence: Dr R Kawamoto, Department of Internal Medicine, Seiyo Municipal Nomura Hospital, 9-53 Nomura, Nomura-cho, Seiyo-city, Ehime 797-1212, Japan. E-mail: rykawamo@m.ehime-u.ac.jp

Received 24 October 2013; revised 16 May 2014; accepted 19 May 2014; published online 26 June 2014 
Candidates with cardiovascular diseases or any other major illnesses that could affect the laboratory test results and exercise routine were excluded. The study consisted of 95 subjects ( 11 men and 84 women) aged $68 \pm 7$ (mean \pm s.d.) years who were on antihypertensive medications (35.8\%), lipid-lowering medications (18.9\%) and antidiabetic medications (15.8\%). Treatments remained unchanged during the intervention. No instructions on eating habits or nutrition were provided and no dietary intervention was administered. The study complies with the Declaration of Helsinki, and was approved by the ethics committee of Ehime University School of Medicine with written informed consent obtained from each subject.

\section{Evaluation of risk factors}

Information on demographic variables and risk factors was collected using the clinical files at baseline and at the completion of 12 weeks of training. Body mass index (BMI) was calculated by dividing weight (in kilograms) by the square of the height (in meters). Triglycerides (TG), low-density lipoprotein cholesterol (LDL cholesterol), high-density lipoprotein cholesterol (HDL cholesterol), high sensitivity C-reactive protein (hsCRP), FPG (fasting plasma glucose) and IRI (immunoreactive insulin) were measured during an overnight fast of more than $11 \mathrm{~h}$. Homeostasis of model assessment of insulin resistance (HOMA-IR) was calculated from FPG and IRI levels using the following formula: $\left(\mathrm{FPG}\left(\mathrm{mg} \mathrm{dl}^{-1}\right) \times \mathrm{IRI}\left(\mathrm{mU} \mathrm{ml}^{-1}\right)\right) / 405 .{ }^{22}$

\section{Estimation of pulse wave analysis}

Measurements of the radial augmentation index (AI) were conducted after the subjects had rested for at least $5 \mathrm{~min}$ in the sitting position. Radial AI was measured in the left radial artery using an automated tonometric method (HEM-9000AI device; Omron Healthcare) in accordance with a previously described methodology. ${ }^{5,23}$ Brachial BP was measured simultaneously in the right brachium with an oscillometric device incorporated into the HEM-9001AI, and the formula used to calculate mean arterial pressure (MAP) was: $\mathrm{MAP}=((2 \times$ diastolic $\mathrm{BP}(\mathrm{DBP}))+$ systolic $\mathrm{BP}(\mathrm{SBP})) / 3$. In brief, the HEM-9000AI device is programmed to automatically determine the pressure of the radial artery to yield the optimal radial arterial waveform. Then, the first peak of radial SBP (SBP1, a marker of the peripheral SBP) and the second peak of radial SBP (SBP2, a marker of the central SBP) are calculated by calibration with the brachial SBP. The SBP1 is the first peak of the peripheral SBP, combined waveform of the incident (ejected) wave and reflected wave from hand, and the SBP 2 is the peak of the summation of peripheral SBP and the reflected wave from the lower body ${ }^{24}$ (Figure 1). SBP1, SBP2 and DBP values are automatically determined using the fourth derivatives for each radial arterial waveform, and averaged. Pulse pressure (PP) is obtained by the formula: $\mathrm{PP}=\mathrm{SBP}-\mathrm{DBP}$. PP2 is also obtained as SBP2 - DBP. ${ }^{5-7}$ The radial AI, a marker of the central AI, is calculated as follows: $\mathrm{PP} 2 / \mathrm{PP} \times 100(\%) ., 23,25$ In the analysis, we used AI corrected at heart rate 75 per min (AI@75) because of a close (negative) link between AI and heart frequency.

\section{Exercise}

Participants were required to take part in three instructor-led sessions per week lasting $120 \mathrm{~min}$, for 12 weeks. Nordic walking is a unique fitness technique that utilizes walking poles to involve the upper body in the exercise, in addition to providing extra support. ${ }^{26}$ Participants were issued poles (KOMPERDELL, Mondsee, Austria) and tutored on the correct technique for using the equipment during the first week, dedicating 120-min sessions to the Nordic walking technique. The pole length used for the Nordic walk was selected and adjusted to permit smooth arm motion, based on the INWA formula $\left(0.68 \times\right.$ body height $\left.(\text { in } \mathrm{cm})^{26}\right)$, and to induce a near right-angle elbow flexion upon pole landing. ${ }^{27}$ The Nordic walking training program was so designed for the participants to be in the aerobic work zone throughout the exercise. Assessment of postintervention dependent variables occurred within 1 week of the final walking session. Two participants dropped out as they were unable to commit to the study and nine participants did not report for the postintervention testing due to personal reasons. Ninety-five participants were included in the final analysis. Before and at the end of the 12-week intervention, functional tests and metabolic profiles were measured.

\section{Statistical analysis}

Data are presented as the mean \pm standard deviation (s.d.) unless otherwise specified, and in the cases of parameters with nonnormal distributions (TG, hsCRP and HOMA-IR) the data are shown as median (interquartile range) values. In all the analyses, parameters with nonnormal distributions were used after log-transformation. Statistical analysis was performed using IBM SPSS Statistics Version 21 (Statistical Package for Social Science Japan, Tokyo, Japan). Twelve-week changes in various factors and BP parameters were calculated by subtracting the baseline values from those at 12 weeks. Differences among baseline and follow-up findings were analyzed by paired t-test. Partial Pearson's correlation and stepwise multiple linear regression analysis were used to estimate changes in the variables and BP parameters. Analysis of covariance was performed using a general linear model approach to determine the association between the confounding factors and BP parameters in these analyses, BP parameters were the dependent variables, the three categories of change in the confounding factors were the fixed factors and significantly confounding factors were added as covariates. The Bonferroni correction is a multiple-comparison correction used when statistical tests are significant. Furthermore, to examine the consistency of the observed association between change in variables and BP parameters, we performed subgroup analyses by age $(<68, \geqslant 68$ years as half of the number of participants),
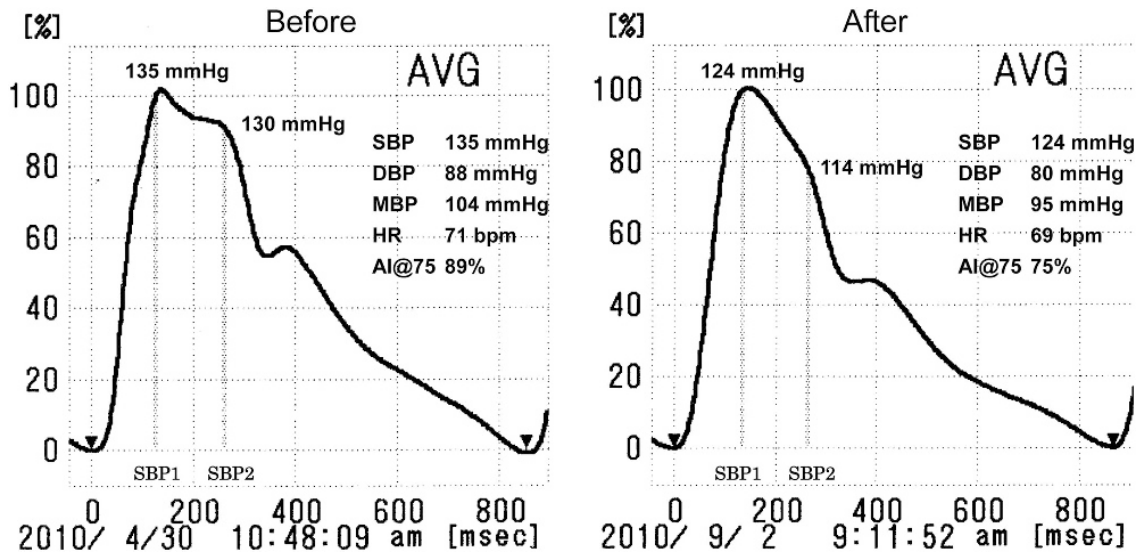

Figure 1 Typical radial waveforms before and after a 12-week walking program in woman aged 62 years. The abbreviation SBP1 indicates the first peak radial SBP (a marker of the peripheral SBP) and SBP2 indicates the second peak radial SBP (a marker of central SBP). The radial augmentation index (AI), a marker of the central Al, was calculated as follows: (SBP2-DBP)/(SBP1-DBP) $\times 100$ (\%). DBP, diastolic blood pressure; SBP, systolic blood pressure. 
BMI $\left(<23, \geqslant 23 \mathrm{~kg} \mathrm{~m}^{-2}\right.$ as below the normal BMI range and the individuals are at increased risk of having metabolic syndrome ${ }^{28}$ ), and antihypertensive/ lipid-lowering/antidiabetic medication (absent, present). Interaction between the change in variables and the subgroups was analyzed by a general linear model. A $P$-value $<0.05$ was considered significant.

\section{RESULTS}

Overall, 95 participants (91\%) completed the 12-week training program and health examination. Baseline variables and the changes at 12 weeks for the participants are shown in Table 1. Participants had a mean body height of $151.4 \pm 7.3$ (range, $136.0-174.5$ ) $\mathrm{cm}$ and a mean BMI of $24.4 \pm 3.1$ (range, 18.7-33.4) $\mathrm{kg} \mathrm{m}^{-2}$. Participants had several cardiovascular risk factors, and baseline BMI, waist circumference, LDL cholesterol, HOMA-IR and brachial BP were at the high end of the normal ranges. After the 12-week training program, body weight, BMI, waist circumference, HDL cholesterol, hsCRP and HOMA-IR decreased significantly, whereas TG and LDL cholesterol were unchanged. The training program significantly reduced their brachial MAP, radial SBP1, radial SBP2 and radial AI@75 by a mean of $4,5,6 \mathrm{~mm} \mathrm{Hg}$, and $2.3 \%$, respectively.

Table 2 shows the relationship between change in body size and changes in metabolic and BP parameters by the 12-week training program. As expected, reductions in body weight and BMI correlated significantly with decrease in TG $(r=0.34, P=0.001 ; r=0.29$, $P=0.005)$ and HOMA-IR $(r=0.49, P<0.001 ; r=0.37, P<0.001)$ (data not shown). They were also strongly correlated with changes in brachial MAP, radial SBP1, SBP2 and AI@75. Figure 2 shows the relationship between changes in body weight and BP parameters. Change in body weight associated significantly with changes in

\section{Table 1 Baseline and follow-up characteristics}

\begin{tabular}{|c|c|c|c|}
\hline Variable $\mathrm{N}=95$ & Baseline & Follow-up & P-value \\
\hline \multicolumn{4}{|l|}{ Body size parameter } \\
\hline Body weight (kg) & $56.4 \pm 9.5$ & $54.1 \pm 8.7$ & $<0.001$ \\
\hline Body mass index $\left(\mathrm{kg} \mathrm{m}^{-2}\right)$ & $24.4 \pm 3.1$ & $23.5 \pm 2.8$ & $<0.001$ \\
\hline Waist circumference $(\mathrm{cm})$ & $86.0 \pm 9.2$ & $83.9 \pm 7.7$ & $<0.001$ \\
\hline \multicolumn{4}{|l|}{ Metabolic parameter } \\
\hline Triglycerides (mg dl ${ }^{-1}$ ) & $95(69-128)$ & $99(68-122)$ & 0.57 \\
\hline LDL cholesterol (mg dl-1) & $132 \pm 29$ & $128 \pm 32$ & 0.06 \\
\hline HDL cholesterol (mg dl-1) & $66 \pm 15$ & $64 \pm 15$ & 0.002 \\
\hline 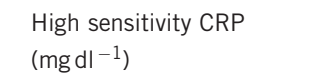 & $\begin{array}{c}0.050(0.030- \\
0.110)\end{array}$ & $\begin{array}{c}0.040(0.020- \\
0.080)\end{array}$ & 0.008 \\
\hline HOMA-IR & $1.19(0.83-2.02)$ & $1.07(0.72-1.48)$ & 0.002 \\
\hline
\end{tabular}

Peripheral blood pressure parameter

\begin{tabular}{lcrr} 
Heart rate (b.p.m.) & $66 \pm 9$ & $64 \pm 9$ & \multicolumn{1}{c}{0.09} \\
Brachial SBP $(\mathrm{mm} \mathrm{Hg})$ & $137 \pm 20$ & $131 \pm 19$ & $<\mathbf{0 . 0 0 1}$ \\
Brachial DBP $(\mathrm{mm} \mathrm{Hg})$ & $77 \pm 11$ & $74 \pm 10$ & $\mathbf{0 . 0 0 3}$ \\
Brachial MAP $(\mathrm{mm} \mathrm{Hg})$ & $97 \pm 12$ & $93 \pm 11$ & $<\mathbf{0 . 0 0 1}$ \\
Radial SBP1 $(\mathrm{mm} \mathrm{Hg})$ & $137 \pm 20$ & $132 \pm 20$ & $\mathbf{0 . 0 0 4}$
\end{tabular}

Central blood pressure parameter

$\begin{array}{lccc}\text { Radial SBP2 (mm Hg) } & 134 \pm 21 & 128 \pm 22 & 0.003 \\ \text { Radial AI@75 (\%) } & 91.4 \pm 9.8 & 89.1 \pm 8.2 & \mathbf{0 . 0 2 0}\end{array}$

Abbreviations: AI@75, augmentation index corrected at heart rate 75 per min; CRP, C-reactive protein; DBP, diastolic blood pressure; HDL, high-density lipoprotein; HOMA-IR, homeostasis of model assessment of insulin resistance; LDL, low-density lipoprotein; MAP, mean arterial pressure; SBP, systolic blood pressure; SBP1: first peak radial systolic blood pressure; SBP2: second peak radial systolic blood pressure. Data are means \pm s.d. Data for triglycerides, high sensitivity CRP, and HOMA-IR were skewed, presented as median (interquartile range) values, and log-transformed for analysis. Statistical significance was assessed by paired $t$-test. and log-transformed for analysis. Statistical
Significant $P$-values are indicated in bold. brachial MAP, radial SBP1, SBP2 and AI@75. In addition, changes in TG also correlated significantly to changes in radial AI@75.

As shown in Table 3, after adjusting for gender, age, height, antihypertensive medication, lipid-lowering medication, antidiabetic medication and all significant variables in Table 2, which were potential covariates, stepwise multivariate linear regression analysis was used to evaluate the contribution of confounding factors for $\mathrm{BP}$ parameters. In this analysis, reduction in body weight was significantly and independently associated with each reduction in brachial MAP, radial SBP1, SBP2 and AI@75.

For comparison between subjects with successful and unsuccessful body weight reduction, Table 4 shows multivariate-adjusted changes in BP parameters categorized by tertiles of change in body weight. Multivariate-adjusted changes in brachial MAP, radial SBP1 and SBP2 showed greater reduction in the changes in body weight group of $\leqslant-2.5 \mathrm{~kg}$ (tertile-1) than those in the group of $\geqslant-1.3 \mathrm{~kg}$ (tertile-3).

Next, to control potential confounding factors by age, BMI and antihypertensive/lipid-lowering/antidiabetic medication, the data were further stratified by age, BMI and medication (Table 5). Each change in body weight was significantly and similarly associated with reduction in radial SBP2. The standardized coefficients for radial SBP2 were significant in both groups. Thus, there were no significant interactions between the two groups regarding those parameters.

\section{DISCUSSION}

After the 12-week training program, metabolic variables and BP parameters improved significantly, and changes in body weight had direct and positive effects on radial SBP2 and AI@75, which closely correlated with central $\mathrm{SBP}^{5,6}$ as well as on radial SBP1 and brachial MAP. Existing studies in elderly persons are generally few and controversial because of age-related differences in the effect of exercise training on $\mathrm{BP}^{29}$ To the best of our knowledge, this is the first study to have demonstrated that weight loss induces central SBP reduction and may be a pathway by which exercise training improves cardiovascular health in elderly persons. This occurred in the absence of significant change to resting heart rate and suggests that Nordic walking is beneficial to cardiovascular health in elderly individuals.

We found that the 12-week training program was associated with marked improvements in body weight $(-2.3 \mathrm{~kg})$, hsCRP $\left(-0.040 \mathrm{mg} \mathrm{dl}^{-1}\right)$, HOMA-IR $(-0.12)$, brachial SBP $(-6 \mathrm{~mm} \mathrm{Hg})$, brachial DBP $(-3 \mathrm{~mm} \mathrm{Hg})$, brachial MAP $(-4 \mathrm{~mm} \mathrm{Hg})$, radial SBP1 $(-5 \mathrm{~mm} \mathrm{Hg})$, radial SBP2 $(-6 \mathrm{~mm} \mathrm{Hg})$, and radial AI $(-2.3 \%)$. Indeed, several recent studies have shown that Nordic walking basedphysical activity interventions can achieve significant improvements in body weight or BMI, risk factors for diabetes and cardiovascular disease. $^{30-32}$ Nordic walking leads to greater adaptations in the cardiovascular and respiratory systems as well as additional benefits in upper-body muscular strength, ${ }^{33}$ and it results in a significant increase in oxygen use and energy consumption, compared with regular walking without poles. ${ }^{34}$ Beck et al. ${ }^{35}$ demonstrated that both resistance and endurance exercise effectively reduce central BP and AI as well as peripheral arterial stiffness in prehypertensive subjects. In overweight or obese individuals, Millen et al. ${ }^{36}$ reported that a 6-week exercise training, which improved cardiorespiratory fitness, decreased brachial SBP and DBP from $142 \pm 8 / 94 \pm 8$ to $134 \pm 11$ / $86 \pm 11 \mathrm{~mm} \mathrm{Hg}(P<0.005 / P<0.005)$ and aortic SBP from $132 \pm 8$ to $124 \pm 12 \mathrm{~mm} \mathrm{Hg}(P<0.002)$. Recent evidence suggested that a $6-\mathrm{mm} \mathrm{Hg}$ reduction in SBP results in a $12.6 \%, 13.2 \%$ and $8.6 \%$ decreased risk in ischemic heart disease, all cardiovascular diseases and all-cause 16-year mortality, respectively. ${ }^{37}$ Therefore, the reductions in peripheral and central SBP in our study may be clinically significant. 
Table 2 Relationship between changes in characteristics and changes in blood pressure parameters after the 12-week training program

Dependent variable

\begin{tabular}{|c|c|c|c|c|}
\hline & $\triangle$ Brachial MAP & $\triangle$ Radial SBP1 & $\triangle$ Radial SBP2 & ARadial Al@75 \\
\hline Independent variable $\mathrm{N}=95$ & Partial r (P-value) & Partial r (P-value) & Partial r (P-value) & Partial r (P-value) \\
\hline \multicolumn{5}{|l|}{ Change in body size parameter } \\
\hline$\Delta$ Body weight & $0.35(0.001)$ & $0.31(0.003)$ & $0.37(<0.001)$ & $0.32(0.002)$ \\
\hline$\Delta$ Body mass index & $0.31(0.003)$ & $0.27(0.011)$ & $0.33(0.002)$ & $0.30(0.004)$ \\
\hline$\Delta$ Waist circumference & $0.01(0.95)$ & $0.10(0.37)$ & $0.13(0.24)$ & $0.16(0.14)$ \\
\hline \multicolumn{5}{|l|}{ Change in metabolic parameter } \\
\hline$\Delta$ Triglycerides & $0.20(0.06)$ & $0.12(0.26)$ & $0.18(0.10)$ & $0.27(0.010)$ \\
\hline$\Delta \mathrm{LDL}$ cholesterol & $0.21(0.05)$ & $0.06(0.58)$ & $0.02(0.83)$ & $-0.02(0.87)$ \\
\hline$\Delta \mathrm{HDL}$ cholesterol & $0.17(0.12)$ & $0.16(0.13)$ & $0.11(0.29)$ & $-0.11(0.30)$ \\
\hline$\Delta$ High sensitivity $\mathrm{CRP}$ & $-0.12(0.25)$ & $-0.16(0.13)$ & $-0.11(0.29)$ & $0.18(0.10)$ \\
\hline$\Delta \mathrm{HOMA}-\mathrm{IR}$ & $0.19(0.08)$ & $0.16(0.13)$ & $0.17(0.11)$ & $0.13(0.24)$ \\
\hline
\end{tabular}

Abbreviations: $\Delta$, follow-up data -baseline data; AI@75, augmentation index corrected at heart rate 75 per min; CRP, C-reactive protein; HDL, high-density lipoprotein; HOMA-IR, homeostasis of model assessment of insulin resistance; LDL, low-density lipoprotein; MAP, mean arterial pressure; $r$, Pearson's correlation coefficientSBP1: first peak radial systolic blood pressure; SBP2: second peak radial systolic blood pressure. Data are adjusted for gender, age, height, antihypertensive medication, lipid-lowering medication and antidiabetic medication. Significant $P$-values are indicated in bold.
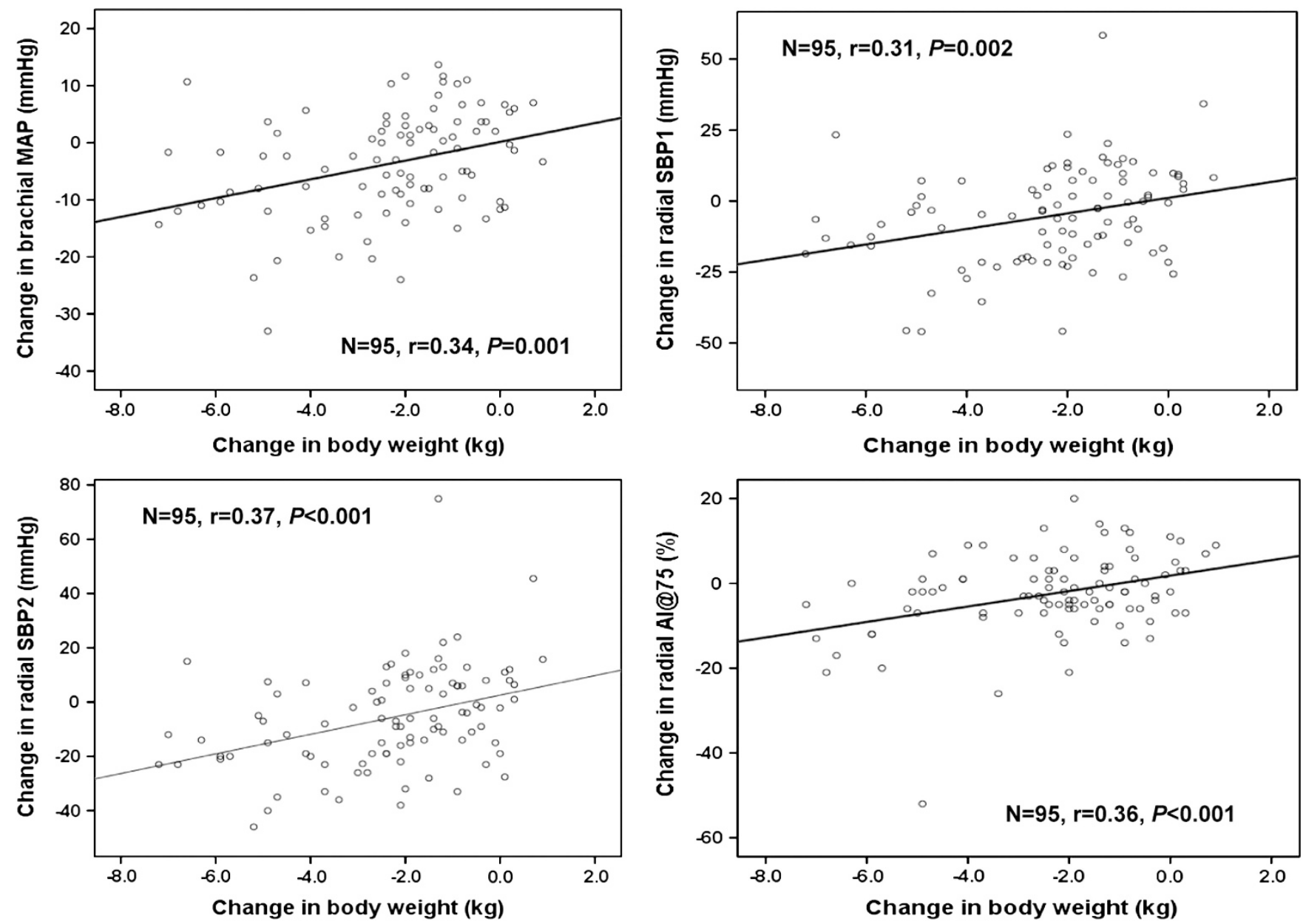

Figure 2 Relationship between changes in body weight and blood pressure parameters after the 12-week Nordic walking training program. The changes in body weight correlated significantly with changes in brachial MAP $(r=0.34, P=0.001)$, radial SBP1 $(r=0.31, P=0.002)$, radial SBP2 $(r=0.37$, $P<0.001)$ and Al@75 $(r=0.36, P<0.001)$. Al, augmentation index; MAP, mean arterial pressure; SBP, systolic blood pressure. 
Table 3 Relationship between changes in characteristics and changes in blood pressure parameters after the 12-week training program

\begin{tabular}{|c|c|c|c|c|}
\hline \multirow{3}{*}{$\begin{array}{l}\text { Independent } \\
\text { variable }\end{array}$} & \multicolumn{4}{|c|}{ Dependent variable } \\
\hline & $\Delta$ Brachial & & & \\
\hline & MAP & $\triangle$ Radial SBP1 & $\triangle$ Radial SBP2 & ARadial Al@75 \\
\hline$N=95$ & $\beta$ (P-value) & $\beta$ (P-value) & $\beta$ (P-value) & $\beta$ (P-value) \\
\hline \multirow{2}{*}{$\begin{array}{l}\Delta \text { Body weight } \\
R^{2}\end{array}$} & $0.34(0.001)$ & $0.31(0.002)$ & $0.37(<0.001)$ & $0.36(0.001)$ \\
\hline & $0.116(0.001)$ & $0.095(0.002)$ & $0.139(<0.001)$ & $0.129(<0.001)$ \\
\hline \multicolumn{5}{|c|}{$\begin{array}{l}\text { Abbreviations: } \Delta \text {, follow-up data-baseline data; Al@75, augmentation index corrected at heart } \\
\text { rate } 75 \text { per min; } \beta \text {, standardized coefficient; MAP, mean arterial pressure; } R^{2} \text {, coefficient of } \\
\text { determination; SBP1: first peak radial systolic blood pressure; SBP2: second peak radial } \\
\text { systolic blood pressure. Data are adjusted for gender, age, height, antihypertensive medication, } \\
\text { lipid-lowering medication, antidiabetic medication and all significant variables in Table } 2 \text { by } \\
\text { stepwise multiple linear regression analysis. Significant } P \text {-values are indicated in bold. }\end{array}$} \\
\hline
\end{tabular}

Table 4 Adjusted changes in blood pressure parameters categorized by tertiles of changes in body weight

\begin{tabular}{|c|c|c|c|c|}
\hline \multirow{3}{*}{$\begin{array}{l}\text { Change in body } \\
\text { weight } \mathrm{N}=95\end{array}$} & \multicolumn{4}{|c|}{ Dependent variable $(\mathrm{mm} \mathrm{Hg})$} \\
\hline & $\triangle$ Brachial & $\Delta$ Radial & & $\Delta$ Radial \\
\hline & MAP & SBP1 & $\triangle$ Radial SBP2 & Al@75 \\
\hline $\begin{array}{l}\text { Tertile-1: }-7.2 \text { to } \\
-2.5 \mathrm{~kg}\end{array}$ & $-8.4 \pm 1.5^{a}$ & $-12.6 \pm 2,8^{a}$ & $\begin{array}{c}-15.0 \pm 3.0^{a} \\
b\end{array}$ & $-5.5 \pm 1.6$ \\
\hline $\begin{array}{l}\text { Tertile-2: }-2.4 \text { to } \\
-1.3 \mathrm{~kg}\end{array}$ & $-1.6 \pm 1.6$ & $-2.8 \pm 3.0$ & $-2.0 \pm 3.2$ & $-1.4 \pm 1.8$ \\
\hline $\begin{array}{l}\text { Tertile-3: }-1.3 \text { to } \\
0.9 \mathrm{~kg}\end{array}$ & $-0.4 \pm 1.5$ & $0.6 \pm 2.9$ & $0.7 \pm 3.1$ & $-0.3 \pm 1.7$ \\
\hline$P$-value & $<0.001$ & 0.004 & 0.001 & 0.06 \\
\hline
\end{tabular}

Abbreviations: $\Delta$, follow-up data - baseline data; AI@75, augmentation index corrected at heart rate 75 per min; MAP, mean arterial pressure; SBP1: first peak radial systolic blood pressure; SBP2: second peak radial systolic blood pressure.

a $P<0.005$ versus tertile- 3 .

$P<0.05$ versus tertile-2.

Data are means \pm s.e.m. Data are adjusted for significant variables in Table 3. Statistical

significance was assessed by analysis of covariance. Post hoc analysis performed by Bonferroni.

Significant $P$-values are indicated in bold.

The precise mechanisms that lead to a reduction in central SBP in individuals with weight loss are not completely understood. Brachial SBP is mainly a product of forward wave pressure, whereas central SBP is particularly influenced by pressure wave reflection, which in turn increases with age and structural changes in arteries, and can directly evaluate left ventricular afterload. ${ }^{38}$ Thus, arterial stiffness is a major determinant of central SBP as well as left ventricular afterload and oxygen requirements and damaging stresses on arterial walls. ${ }^{39}$ Higashino et al. ${ }^{40}$ demonstrated that central SBP was significantly decreased following weight loss by 12 -week lifestyle modification, and there was a significant correlation between the change in central SBP and that in arterial stiffness in overweight and obese men. Only a few studies have evaluated mechanisms other than BP reduction by which weight loss may reduce arterial stiffness, which is the primary reflect of central SBP and AI@75. Endurance and strength training (for example, Nordic walking) have well-known cardiovascular adaptations and lead to hypertrophy and increased capillary density in the muscles. ${ }^{14}$ This improvement might be caused by the improvement in endothelial function, as assessed by a decrease in endothelin-1, changes in local renin-angiotensin-aldosterone system activity, and an increase in nitric oxide levels and improvements
Table 5 Relationship between changes in body weight and second peak radial systolic blood pressure after the 12-week training program within selected subgroups

\begin{tabular}{|c|c|c|c|}
\hline \multirow[b]{2}{*}{ Baseline variable } & \multicolumn{3}{|c|}{$\Delta$ Body weight } \\
\hline & $\mathrm{N}=95$ & $\beta$ (P-value) & P-interaction \\
\hline \multicolumn{4}{|l|}{ Age } \\
\hline$<68$ years & $N=49$ & $0.38(0.007)$ & 0.21 \\
\hline$\geqslant 68$ years & $N=46$ & $0.40(0.007)$ & \\
\hline \multicolumn{4}{|l|}{ Body mass index } \\
\hline$<23 \mathrm{~kg} \mathrm{~m}^{-2}$ & $N=34$ & $0.55(0.001)$ & 0.22 \\
\hline$\geqslant 23 \mathrm{~kg} \mathrm{~m}^{-2}$ & $N=61$ & $0.33(0.009)$ & \\
\hline \multicolumn{4}{|l|}{ Medication } \\
\hline Absence & $N=48$ & $0.45(0.001)$ & 0.94 \\
\hline Presence & $N=47$ & $0.36(0.014)$ & \\
\hline
\end{tabular}

$\Delta$ indicates follow-up data - baseline data. Medication includes antihypertensive medication, lipid-lowering medication and antidiabetic medication. Statistical significance was assessed by analysis of covariance.

in sympathovagal balance, after exercise training-induced weight loss. $^{41,42}$ In addition, high-intensity resistance training has shown that changes in central SBP are positively correlated with changes in oxidized LDL and soluble E-selectin in overweight or obese subjects. ${ }^{43}$ Tycho Vuurmans et al. ${ }^{44}$ found that weight loss may partly trigger a decrease in circulating blood volume subsequent to the improvement in AI.

Some limitations of this study must be considered. First, a 12-week program may potentially be too brief for evaluating the effects of walking training on BP parameters. Long-term studies of similar exercise intensity and frequency are warranted to elucidate whether Nordic walking may be a sustainable mode of exercise. Second, the daily physical activity of participants in our study, before entry and during the study, was not controlled or matched. Third, although we have comprehensively adjusted for confounders such as gender, age, body sizes, lipids, markers of inflammation (for example, hsCRP) and HOMA-IR in the association of BP parameters, other important parameters such as markers of endothelial dysfunction are absent. Fourth, we could not eliminate possible effects of the underlying diseases and medication, especially antihypertensive and lipidlowering medication use, on the results. Comparison of participants taking medication with those not taking medication revealed that there were no differences regarding effect of weight loss on change in radial SBP2. Fifth, we measured brachial BP on the right upper arm and arterial waveform on the left radial artery based on mechanical directions. Thus, we could not eliminate possible effects of arterial stenosis. Sixth, this study is not a randomized study, which is a weak point. Therefore the demographics and referral source may limit generalizability. These points need to be addressed again in a large population-based randomized sample in a prospective manner.

In conclusion, the results of this study suggest that weight loss by a 12 -week training program may be an effective strategy to improve BP parameters among Japanese elderly persons. It is also possible that elderly patients are likely to have the greatest improvements in central SBP from clinical interventions that are focused on weight loss, which induces central SBP reduction.

\section{CONFLICT OF INTEREST}

The authors declare no conflict of interest. 


\section{ACKNOWLEDGEMENTS}

This work was supported in part by a grant-in-aid for Scientific Research from the Foundation for Development of Community (2013).

Author contributions: RK participated in the design of the study, performed the statistical analysis and wrote the first draft of the manuscript. All authors reviewed and edited the manuscript and approved the final version of the manuscript.

1 Roman MJ, Devereux RB, Kizer JR, Lee ET, Galloway JM, Ali T, Umans JG, Howard BV. Central pressure more strongly relates to vascular disease and outcome than does brachial pressure: the Strong Heart Study. Hypertension 2007; 50 197-203.

2 Pini R, Cavallini MC, Palmieri V, Marchionni N, Di Bari M, Devereux RB, Masotti G, Roman MJ. Central but not brachial blood pressure predicts cardiovascular events in an unselected geriatric population: the ICARe Dicomano Study. J Am Coll Cardiol 2008; 51: 2432-2439.

3 Roman MJ, Okin PM, Kizer JR, Lee ET, Howard BV, Devereux RB. Relations of central and brachial blood pressure to left ventricular hypertrophy and geometry: the Strong Heart Study. J Hypertens 2010; 28: 384-388.

4 Williams B, Lacy PS, Thom SM, Cruickshank K, Stanton A, Collier D, Hughes AD, Thurston H, O'Rourke M. Differential impact of blood pressure-lowering drugs on central aortic pressure and clinical outcomes: principal results of the Conduit Artery Function Evaluation (CAFE) study. Circulation 2006; 113 1213-1225.

5 Takazawa K, Kobayashi H, Shindo N, Tanaka N, Yamashina A. Relationship between radial and central arterial pulse wave and evaluation of central aortic pressure using the radial arterial pulse wave. Hypertens Res 2007; 30: 219-228.

6 Takazawa K, Kobayashi H, Kojima I, Aizawa A, Kinoh M, Sugo Y, Shimizu M, Miyawaki Y, Tanaka N, Yamashina A, Avolio A. Estimation of central aortic systolic pressure using late systolic inflection of radial artery pulse and its application to vasodilator therapy. J Hypertens 2012; 30: 908-916.

7 Miyashita H. Clinical assessment of central blood pressure. Curr Hypertens Rev 2012 8: 80-90.

8 Dorresteijn JA, Spiering W, Van Der Graaf Y, Visseren FLSMART Study Group. Relation between adiposity and hypertension persists after onset of clinically manifest arterial disease. J Hypertens 2012; 30: 2331-2337.

9 Doll S, Paccaud F, Bovet P, Burnier M, Wietlisbach V. Body mass index, abdominal adiposity and blood pressure. Consistency of their association across developing and developed countries. Int J Obes Relat Metab Disord 2002; 26: 48-57.

10 Shaw K, Gennat H, O'Rourke P, Del Mar C. Exercise for overweight or obesity. Cochrane Database Syst Rev 2006; 4: CD003817.

11 Semlitsch T, Jeitler K, Hemkens LG, Horvath K, Nagele E, Schuermann C, Pignitter N, Herrmann KH, Waffenschmidt S, Siebenhofer A. Increasing physical activity for the treatment of hypertension: a systematic review and meta-analysis. Sports Med 2013 43: 1009-1023.

12 Shimokata H, Andres R, Coon PJ, Elahi D, Muller DC, Tobin JD. Studies in the distribution of body fat. II. Longitudinal effects of change in weight. Int J Obes 1989, 13: 455-464.

13 Canoy D, Wareham N, Luben R, Welch A, Bingham S, Day N, Khaw KT. Serum lipid concentration in relation to anthropometric indices of central and peripheral fat distribution in 20021 British men and women: results from the EPIC-Norfolk population-based cohort study. Atherosclerosis 2006; 189: 420-427.

14 Canoy D, Luben R, Welch A, Bingham S, Wareham N, Day N, Khaw KT. Fat distribution, body mass index and blood pressure in 22090 men and women in the Norfolk cohort of the European Prospective Investigation into Cancer and Nutrition (EPIC-Norfolk) study. J Hypertens 2004; 22: 2067-2074.

15 Kohrt WM, Obert KA, Holloszy JO. Exercise training improves fat distribution patterns in 60- to 70-year-old men and women. J Gerontol 1992; 47: M99-M105.

16 Slentz CA, Duscha BD, Johnson JL, Ketchum K, Aiken LB, Samsa GP, Houmard JA, Bales CW, Kraus WE. Effects of the amount of exercise on body weight, body composition, and measures of central obesity: STRRIDE-a randomized controlled study. Arch Intern Med 2004; 164: 31-39.

17 Stewart KJ, Bacher AC, Turner KL, Fleg JL, Hees PS, Shapiro EP, Tayback M, Ouyang P. Effect of exercise on blood pressure in older persons: a randomized controlled trial. Arch Intern Med 2005; 165: 756-762.

18 Maple-Brown LJ, Piers LS, O'Rourke MF, Celermajer DS, O'Dea K. Central obesity is associated with reduced peripheral wave reflection in Indigenous Australians irrespective of diabetes status. J Hypertens 2005; 23: 1403-1407.
19 Otsuka T, Kawada T, Ibuki C, Kusama Y. Obesity as an independent influential factor for reduced radial arterial wave reflection in a middle-aged Japanese male population. Hypertens Res 2009; 32: 387-391.

20 Tabara Y, Saito I, Nishida W, Kohara K, Sakurai S, Kawamura R, Onuma H, Takata Y, Osawa H, Miki T, Tanigawa T. Relatively lower central aortic pressure in patients with impaired insulin sensitivity and resistance: the Toon Health Study. J Hypertens 2011; 29: 1948-1954.

21 Bradley U, Spence M, Courtney CH, McKinley MC, Ennis CN, McCance DR, McEneny J, Bell PM, Young IS, Hunter SJ. Low-fat versus low-carbohydrate weight reduction diets: effects on weight loss, insulin resistance, and cardiovascular risk: a randomized control trial. Diabetes 2009; 58: 2741-2748.

22 Matthews DR, Hosker JP, Rudenski AS, Naylor BA, Treacher DF, Turner RC Homeostasis model assessment: insulin resistance and beta-cell function from fasting plasma glucose and insulin concentrations in man. Diabetologia 1985; 28: 412-419.

23 Kohara K, Tabara Y, Oshiumi A, Miyawaki Y, Kobayashi T, Miki T. Radial augmentation index: a useful and easily obtainable parameter for vascular aging. Am J Hypertens 2005; 18: 11S-14S.

24 Nichols WW. Clinical measurement of arterial stiffness obtained from noninvasive pressure waveforms. Am J Hypertens 2005; 18: 3S-10S.

25 Tomita H, Kawamoto R, Tabara Y, Miki T, Kohara K. Blood pressure is the main determinant of the reflection wave in patients with type 2 diabetes. Hypertens Res 2008; 31: 493-499.

26 Sugiyama K, Kawamura M, Tomita H, Katamoto S. Oxygen uptake, heart rate, perceived exertion, and integrated electromyogram of the lower and upper extremities during level and Nordic walking on a treadmill. J Physiol Anthropol 2013; 32: 2.

27 Schwameder H, Roithner R, Muller E, Niessen W. Knee joint forces during downhill walking with hiking poles. J Sports Sciences 1999; 17: 969-978.

28 Kawamoto R, Ohtsuka N, Ninomiya D, Nakamura S. Carotid atherosclerosis in normal-weight metabolic syndrome. Intern Med 2007; 46: 1771-1777.

29 Montain SJ, Jilka SM, Ehsani AA, Hagberg JM. Altered hemodynamics during exercise in older essential hypertensive subjects. Hypertension 1988; 12: 479-484.

30 Eriksson MK, Franks PW, Eliasson M. A 3-year randomized trial of lifestyle intervention for cardiovascular risk reduction in the primary care setting: the Swedish Björknäs study. PLoS One 2009; 4: e5195.

31 Tschentscher M, Niederseer D, Niebauer J. Health benefits of Nordic walking: a systematic review. Am J Prev Med 2013; 44: 76-84.

32 Figard-Fabre H, Fabre N, Leonardi A, Schena F. Efficacy of Nordic walking in obesity management. Int J Sports Med 2011; 32: 407-414.

33 Takeshima N, Islam MM, Rogers ME, Rogers NL, Sengoku N, Koizumi D, Kitabayashi Y, Imai A, Naruse A. Effects of nordic walking compared to conventional walking and band-based resistance exercise on fitness in older adults. J Sports Sci Med 2013; 12: 422-430.

34 Church TS, Earnest CP, Morss GM. Field testing of physiological responses associated with Nordic Walking. Res Q Exerc Sport 2002; 73: 296-300.

35 Beck DT, Martin JS, Casey DP, Braith RW. Exercise training reduces peripheral arteria stiffness and myocardial oxygen demand in young prehypertensive subjects. $A m \mathrm{~J}$ Hypertens 2013; 26: 1093-1102.

36 Millen AM, Norton GR, Avidon I, Woodiwiss AJ. Effects of short-term exercise-training on aortic systolic pressure augmentation in overweight and obese individuals. Eur $J$ Appl Physiol 2013; 113: 1793-1803.

37 Stamler J. The INTERSALT Study. Background, methods, findings, and implications. Am J Clin Nutr 1997; 65: 626S-642S.

38 Safar ME, Levy BI, Struijker-Boudier H. Current perspectives on arterial stiffness and pulse pressure in hypertension and cardiovascular diseases. Circulation 2003; 107 2864-2869.

39 O'Rourke M. Arterial stiffness, systolic blood pressure, and logical treatment of arterial hypertension. Hypertension 1990; 15: 339-347.

40 Higashino R, Miyaki A, Kumagai $H$, Choi $Y$, Akazawa N, Ra SG, Tanabe $Y$, Eto M, So R, Tanaka K, Ajisaka R, Maeda S. Effects of lifestyle modification on central blood pressure in overweight and obese men. Blood Press Monit 2013; 18: 311-315.

41 Miyaki A, Maeda S, Yoshizawa M, Misono M, Saito Y, Sasai H, Kim MK, Nakata Y, Tanaka K, Ajisaka R. Effect of habitual aerobic exercise on body weight and arterial function in overweight and obese men. Am J Cardiol 2009; 104: 823-828.

42 Zieman SJ, Melenovsky V, Kass DA. Mechanisms, pathophysiology, and therapy of arterial stiffness. Arterioscler Thromb Vasc Biol 2005; 25: 932-943.

43 Croymans DM, Krell SL, Oh CS, Katiraie M, Lam CY, Harris RA, Roberts CK. Effects of resistance training on central blood pressure in obese young men. J Hum Hyperten 2013; 28: 157-164.

44 Tycho Vuurmans JL, Boer WH, Bos WJ, Blankestijn PJ, Koomans HA. Contribution of volume overload and angiotensin II to the increased pulse wave velocity of hemodialysis patients. J Am Soc Nephrol 2002; 13: 177-183. 